\title{
Hemolytic-uremic Syndrome Complicating Acute Pancreatitis
}

\author{
Narinder Pal Singh, Neeru P. Aggarwal, Hardik R. Shah, Laxmi Kant Jha, Anish Kumar \\ Department of Internal Medicine and Nephrology, Max Super Speciality Hospital, Ghaziabad, Uttar Pradesh, India
}

\section{Abstract}

Hemolytic-uremic syndrome (HUS) is characterized by acute kidney injury with hemolytic anemia and thrombocytopenia. It has diverse etiologies, clinical manifestations, and risk factors. Acute pancreatitis as a cause of HUS is rare in adults. We report a case of 32-year-old male who presented with ethanol-induced acute pancreatitis complicated with hemolytic-uremic syndrome managed with hemodialysis and plasmapheresis.

Keywords: Acute kidney injury, hemodialysis, plasmapheresis, thrombotic thrombocytopenic purpura

\section{INTRODUCTION}

The incidence of acute kidney injury in patients with acute pancreatitis carries a poor prognosis. Hemolytic-uremic syndrome (HUS) is characterized by nonimmune hemolytic anemia, thrombocytopenia, and renal failure caused by platelet thrombi in the microcirculation of the kidney. HUS as a result of alcoholic pancreatitis is scarcely reported ${ }^{[1]}$ We report a case of alcoholic pancreatitis complicated with renal dysfunction followed by HUS, successfully managed with plasmapheresis after early recognition.

\section{Case Report}

A 32-year-old male was admitted to hospital with complaints of abdominal pain, distension, vomiting, and reduce urine output. He had consumed alcohol in a substantial amount at a party, night before the onset of symptoms. He was a known hypertensive, controlled on low-dose amlodipine, otherwise healthy. On examination, the patient was afebrile, pale, dehydrated with tender, distended abdomen, and hypoactive bowel sounds. Ultrasonography of the abdomen revealed mild fatty liver and mild ascites with pancreas obscured by overlying gas-filled loops. Over the next 2 days, he became jaundiced and oliguric. Renal functions deteriorated with increase in urea and creatinine. He had an abrupt decrease in hemoglobin and platelet count and increased in serum bilirubin [Table 1]. Further evaluation revealed raised levels of procalcitonin, normal coagulation profile, and negative stool for occult blood.

\begin{tabular}{|l|l|}
\hline \multicolumn{3}{c|}{ Access this article online } \\
\hline Quick Response Code: & Website: \\
& www.ijccm.org \\
& \\
&
\end{tabular}

His peripheral blood film revealed numerous fragmented red cells and schistocytes.

In view of Coombs-negative hemolytic anemia, thrombocytopenia, and acute renal failure with schistocytes on blood smear, a diagnosis of HUS was made complicating acute pancreatitis. On the $3^{\text {rd }}$ day, he was initiated on plasmapheresis: $2 \mathrm{~L}$ of plasma exchange per cycle $(30 \mathrm{ml} /$ $\mathrm{kg}$ ) supplemented with albumin and fresh frozen plasma product transfusions as replacement fluids. In due course, three sessions of hemodialysis and four sessions of plasmapheresis were provided to him on alternate days, also requiring additional two units of blood transfusions. He was managed with empirical intravenous antibiotics and total parenteral nutrition (TPN) for initial 5 days. Culture (blood and urine) reports were sterile.

By the $7^{\text {th }}$ day, there was substantial improvement in clinical condition with significant increase in urine output. Laboratory parameters improved with hemoglobin, increased platelet count, reduction in urea, creatinine, and total bilirubin level. By the $10^{\text {th }}$ day, the patient was shifted out to wards and was discharged in stable condition by the $14^{\text {th }}$ day on oral antibiotics.

\section{Address for correspondence: Dr. Narinder Pal Singh, Department of Internal Medicine and Nephrology, Max Super Speciality Hospital, Vaishali, Ghaziabad - 201 012, Uttar Pradesh, India. E-mail: nanusingh58@gmail.com}

This is an open access article distributed under the terms of the Creative Commons Attribution-NonCommercial-ShareAlike 3.0 License, which allows others to remix, tweak, and build upon the work non-commercially, as long as the author is credited and the new creations are licensed under the identical terms.

For reprints contact: reprints@medknow.com

How to cite this article: Singh NP, Aggarwal NP, Shah HR, Jha LK, Kumar A. Hemolytic-uremic syndrome complicating acute pancreatitis. Indian J Crit Care Med 2017;21:534-6. 


\begin{tabular}{|c|c|c|c|c|}
\hline Investigations & Day $1^{\text {st }}$ & Day $3^{\text {rd }}$ & Day $7^{\text {th }}$ & Day $14^{\text {th }}$ \\
\hline Hemoglobin (g/dl) & 12 & 9.5 & 8 & 9 \\
\hline TLC (cells/ccm) & 17,000 & & & \\
\hline Platelet count (cells/ccm) & 70,000 & 60,000 & 3.5 lakhs & \\
\hline Urea (mg/dl) & 85 & 94 & 37 & \\
\hline Creatinine (mg/dl) & 4.6 & 5.4 & 1.1 & 0.8 \\
\hline Uric acid (mg/dl) & 9.7 & & & \\
\hline Total bilirubin (mg/dl) & 2.5 & 6 & 1 & \\
\hline Direct bilirubin (mg/dl) & 1.9 & & & \\
\hline Albumin (g/dl) & 3 & & & \\
\hline ALT (IU/L) & 18 & & & \\
\hline AST (IU/L) & 52 & & & \\
\hline Amylase (IU/L) & 1320 & & & 120 \\
\hline Lipase (IU/L) & 1339 & & & 418 \\
\hline Procalcitonin (ng/ml) & & 2.28 & 0.35 & \\
\hline Retic count & & $3.5 \%$ & & \\
\hline LDH (U/L) & & 2185 & & \\
\hline G6PD screening & & Normal & & \\
\hline Direct Coombs test & & Negative & & \\
\hline Haptoglobin (mg/dl) & & 30 & & \\
\hline $\operatorname{FDP}(\mathrm{mcg} / \mathrm{ml})$ & & $>20$ & & \\
\hline ANA, C-ANCA, p-ANCA & & Negative & & \\
\hline IgA levels (mg/dl) & & 173 & & \\
\hline \multicolumn{5}{|c|}{$\begin{array}{l}\text { TLC: Total leukocyte count; ALT: Alanine transaminase; AST: Aspartate } \\
\text { transaminase; LDH: Lactate dehydrogenase; FDP: Fibrin degradation } \\
\text { product; ANA: antinuclear antibody; C-ANCA: Cytoplasmic-Antineutrophil } \\
\text { cytoplasmic antibodies; p-ANCA: Perinuclear- Antineutrophil cytoplasmic } \\
\text { antibodies }\end{array}$} \\
\hline
\end{tabular}

\section{Discussion}

HUS and thrombotic thrombocytopenic purpura (TTP) are classified into a group of disorders called thrombotic microangiopathies. ${ }^{[2]}$ The term "HUS" was coined by Gasser et al. in 1955 and describes an illness consisting of acute renal failure accompanied by nonimmune hemolytic anemia and thrombocytopenia. ${ }^{[3]}$ HUS is most commonly seen in children, but cases among adults have also been increasingly described in association with infections, transplants, autoimmune diseases, drugs, and neoplasms. It is divided as typical HUS (Shiga-like toxin-associated HUS) and atypical HUS (non-Shiga-like toxin-associated HUS). Atypical HUS is further subclassified as familial due to complement dysregulation and sporadic due to Streptococcus pneumoniae infection. ${ }^{[4-6]}$

The etiology of HUS following pancreatitis is not clearly understood as there are only few cases reported in the literature. Swisher et al. described patients who were diagnosed with acute pancreatitis and then subsequently developed an acute episode of TTP-HUS. ${ }^{[1]}$

Several hypotheses have proposed the role of inflammatory mediators, tumor necrosis factor and interleukin (IL)-1, that can induce widespread vascular endothelial injury. ${ }^{[7]}$

Circulating pancreatic proteases interact with a number of components of the coagulation system. They induce clotting factor activation precipitating disseminated intravascular coagulation and also proteolyse the fibrinogen resulting in dysfibrinogenemia. It is proposed that in cases of HUS-TTP secondary to pancreatitis, circulating proteases may modify circulating von Willebrand factor (vWF) molecules enabling spontaneous binding to platelet membrane glycoproteins with subsequent platelet aggregation. ${ }^{[8]}$ Serum estimation of vWF-cleaving protease (ADAMTS-13) has been used to differentiate between TTP and HUS as patients with TTP have deficient ADAMTS-13 activity in plasma compared to patients with HUS. ${ }^{[9]}$ However, in our patient, levels could not be measured due to unavailability of test at center.

The treatment of HUS following acute pancreatitis is primarily supportive. Exchange plasmapheresis has been reported to be an effective treatment with a response rate of $79 \% .{ }^{[10]}$ Rituximab (anti-CD20 antibody) is an alternative treatment option in refractory or relapsing HUS. ${ }^{[1]}$

CRRT/SLED is the preferred treatment for acute kidney injury in intensive care units. It removes metabolic waste products and eliminates inflammatory mediators such as IL-1, IL-6, and IL-8 which contributes to early recovery, as in our case. ${ }^{[12,13]}$

In conclusion, it is important that physicians recognize thrombotic microangiopathy (HUS/TTP) as one of the potential causes of acute renal failure among adult patients with acute pancreatitis, especially in the setting of anemia and thrombocytopenia. Till date, a total of 22 cases have been described to develop HUS/TTP following pancreatitis of varied etiology. Our patient had an excellent response to hemodialysis and plasma exchange with complete resolution of his microangiopathy and recovery of renal function.

\section{Financial support and sponsorship}

Nil.

\section{Conflicts of interest}

There are no conflicts of interest.

\section{ReFERENCES}

1. Swisher KK, Doan JT, Vesely SK, Kwaan HC, Kim B, Lämmle B, et al. Pancreatitis preceding acute episodes of thrombotic thrombocytopenic purpura-hemolytic uremic syndrome: Report of five patients with a systematic review of published reports. Haematologica 2007;92:936-43.

2. Liu J, Hutzler M, Li C, Pechet L. Thrombotic thrombocytopenic purpura (TTP) and hemolytic uremic syndrome (HUS): The new thinking. J Thromb Thrombolysis 2001;11:261-72.

3. Gasser C, Gautier E, Steck A, Siebenmann RE, Oechslin R. Hemolyticuremic syndrome: Bilateral necrosis of the renal cortex in acute acquired hemolytic anemia. Schweiz Med Wochenschr 1955;85:905-9.

4. Karpman D, Papadopoulou D, Nilsson K, Sjögren AC, Mikaelsson C, Lethagen $\mathrm{S}$, et al. Platelet activation by Shiga toxin and circulatory factors as a pathogenetic mechanism in the hemolytic uremic syndrome. Blood 2001;97:3100-8.

5. Tostivint I, Mougenot B, Flahault A, Vigneau C, Costa MA, Haymann JP, et al. Adult haemolytic and uraemic syndrome: Causes and prognostic factors in the last decade. Nephrol Dial Transplant 2002;17:1228-34.

6. Remuzzi G. Hemolytic uremic syndrome: Past and present. Am J Kidney Dis 2000;36:LIV-VI.

7. Silva VA. Thrombotic thrombocytopenic purpura/hemolytic uremic syndrome secondary to pancreatitis. Am J Hematol 1995;50:53-6. 
8. Consonni R, Falanga A, Barbui T. Further characterization of platelet-aggregating cysteine proteinase activity in thrombotic thrombocytopenic purpura. Br J Haematol 1994;87:321-4.

9. Furlan M, Robles R, Galbusera M, Remuzzi G, Kyrle PA, Brenner B, et al. Von Willebrand factor-cleaving protease in thrombotic thrombocytopenic purpura and the hemolytic-uremic syndrome. N Engl J Med 1998;339:1578-84.

10. Chang JC, Kathula SK. Various clinical manifestations in patients with thrombotic microangiopathy. J Investig Med 2002;50:201-6.
11. Gourley BL, Mesa H, Gupta P. Rapid and complete resolution of chemotherapy-induced thrombotic thrombocytopenic purpura/hemolytic uremic syndrome (TTP/HUS) with rituximab. Cancer Chemother Pharmacol 2010;65:1001-4.

12. Prowle JR, Bellomo R. Continuous renal replacement therapy: Recent advances and future research. Nat Rev Nephrol 2010;6:521-9.

13. Fu P, Yuan AH, Wang CH, Li X, Wu HY. Alcohol-induced severe acute pancreatitis followed by hemolytic uremic syndrome managed with continuous renal replacement therapy. BMC Nephrol 2014;15:1. 